This work has been submitted to NECTAR, the Northam pton Electronic Collection of Theses and Research.

\title{
Article
}

Title: Do resource bases enable social inclusion of stu a mainstream secondary school?

Creators: Landor, F. and Perepa, P.

DOI: $10.1111 / 1467-9604.12158$

Example citation: Land an inclusion of students Support for Learing. Asperge

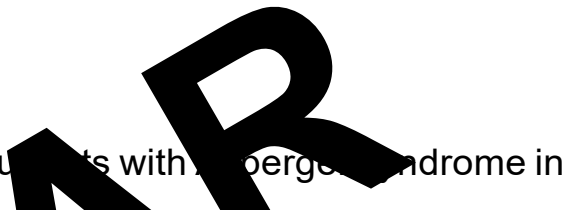
It is advis to re to version if you intend to cite from this work. Version:

Official URL: p://onlinelibrary.wiley.com/doi/10.1111/sufl.2017.32.issue-2/issuetoc

Note: This is the peer reviewed version of the article, which has been published in final form at http://dx.doi.org/10.1111/1467-9604.12158. This article may be used for noncommercial purposes in accordance with Wiley Terms and Conditions for SelfArchiving.

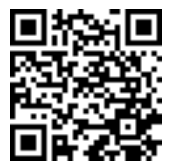




\section{Do resource bases enable social inclusion of students with Asperger syndrome in a mainstream secondary school?}

\section{Introduction}

The international movement towards inclusion has seen legislation in the UK geared towards educating children with special educational needs (SEN) in mainstream schools. Whilst it is agreed that the primary principle of inclusive education is that all children should have the opportunity to learn together, definitions of inclusion have developed from meaning simply to integrate pupils with SEN in mainstream schools (Lewis, 1993), to putting direct responsibility on schools to accommodate for the needs of all students and to embrace their diversity (Rix et al., 2009). Successful inclusion has often been measured by the academic achievement of pupils with SEN (Farrell et al., 2007) and by the impact of inclusion on pupils without SEN (Kalambouka et al., 2007). The current research is concerned with inclusion in terms of the social experience for students with Asperger syndrome and considers that the goal of social inclusion is 'promoting and maintaining acceptance and friendships' for these students in the mainstream school environment (Boutot, 2007, p.156).

\section{Asperger syndrome and inclusion}

It is often stated that pupils with SEN benefit both socially and academically from being educated alongside their mainstream peers (Dybvik, 2004; Farrell, 2001), however, others argue that it can lead to poorer social outcomes for such children, particularly for those on the autism spectrum (Warnock, 2010). Given that difficulties in social development are a central characteristic of people with Asperger syndrome it can be understood why the demands of the social environment in school can be problematic for them. Research has shown that typical characteristics, such as social naivety, social anxiety and problems with social interaction are more likely to lead to bullying (Cappadocia et al., 2012), loneliness (Locke et al., 2010) social exclusion by peers (Symes and Humphrey, 2010; Wainscot et al., 2008) and in some cases even exclusion from school (Humphrey, 2008).

The secondary school environment can be particularly difficult for students with Asperger syndrome due to the consistent changes throughout the day (Moore, 
2007), the increased complexities of social groupings in adolescents (Tobias, 2009) and the noisy and chaotic environment (Humphrey and Parkinson, 2006). It is recognised that schools must have practices in place in order to meet the needs of individuals with Asperger syndrome, however it is also widely acknowledged that no single intervention can meet the varying needs of all the students on the spectrum in a school (Jones et al., 2008). Therefore, it is useful to recognise some of the principles which help schools to promote social inclusion for these students.

Lack of peer awareness is consistently reported in literature as a significant factor contributing to the social exclusion of students with autism (Jones and Frederickson, 2010; Humphrey, 2008). It has been suggested that schools can address this issue by tactfully raising awareness of the condition in order to improve understanding amongst peers and promote social inclusion (Locke et al., 2010).

As well as improving peer awareness, Jones and Frederickson (2010) suggest that school practices should seek to include strategies which improve the social skills of pupils on the spectrum. While it is anticipated that children with autism will benefit socially from being educated in the mainstream (Frederickson and Furnham 2004; Farrell, 2001), literature suggests that specific social skills training is required in order to promote an understanding of the social rules for everyday behaviour which these students do not understand naturally (Myles and Simpson, 2001).

Humphrey (2008) recognises that making changes to the school environment can be beneficial in promoting the social inclusion of pupils on the spectrum. Considering that these students prefer to have consistency and routine, autism friendly environments are intended to reduce stress and enable social adjustment for them (Jordan, 2005). Particular attention is given in the literature to difficulties which may arise during unstructured times (Tobias, 2009; Wainscot et al., 2008). In their study, Wainscot et al., (2008) found that students with Asperger syndrome in a secondary school mostly spent break times in classrooms or the school library. Tobias (2009) used focus groups with students with autism, which highlighted the availability of quiet spaces as a useful place to escape the noise and feel secure. Both studies indicate that students on the spectrum prefer to spend unstructured times in a safe, quiet environment which can be considered by some as contrary to the aim of social inclusion by some people. 
Research also suggests that teachers play a critical role (Park and Chitiyo, 2009; Thorpe and Shafiul Azam, 2010) in making inclusion a success, hence the majority of the research focuses on teachers perceptions and beliefs. For example, Avramidis and Norwich (2002) found that the type of disability and the perceived level of support were the main factors in influencing teacher perceptions of inclusion. Emam and Farrell (2009) found that teachers base their perceptions about the success of inclusion on the level of support which is available in school. This suggests that, as also found by Humphrey and Lewis (2008), a positive school ethos can have a critical role in promoting the inclusion of children on the spectrum.

Emam and Farrell's (2009) research also raised the issue that teaching assistants have varying roles in educational settings. The role of learning support assistants (LSAs) has been highlighted in government policies as an essential support for pupils with SEN (DfE, 2011). In a systematic review of support staff in mainstream schools, Alborz et al., (2009) concluded that LSAs needed to find a balance between encouraging learning and participation, and the possible impact of their presence on the pupils' social interaction in the classroom. These findings, based mainly on primary schools, incite the need for further research on the impact of having an LSA on the social inclusion for students with Asperger syndrome in mainstream secondary schools where the students are likely to be more aware of being different.

Resourced provisions in mainstream schools are often suggested as the best model (Jordan, 2008; Ofsted, 2006). Frederickson et al., (2010) conducted a study which compared the provision for pupils on the autism spectrum in schools with and without a resourced unit, which showed that the features of schools with a specialist unit were related to parental satisfaction. Considering the views of parents is considered as a key component of service provision under various legislations in the UK. It is suggested that parental satisfaction is influenced by the level of staff training and expertise about autism (Frederickson et al., 2010). Similarly, Whitaker (2007) found that parents were most satisfied with provision when school staff understood and empathised with their children's difficulties, and when the schools' responses to individual needs were flexible.

The proposed research questions were designed in order to build upon the existing knowledge around factors which facilitate social inclusion of students with Asperger 
syndrome and evaluate whether a resource base can enhance or hinder this process within a secondary school setting. The specific research questions are:

- What practices are in place to promote the social inclusion of students with Asperger syndrome?

- How is the social experience of schooling for these students perceived by members of staff?

- How do parents of these children perceive their child's schooling experience in terms of social experience?

\section{Methodology and methods}

A case study approach was chosen as it provides an intense and focused exploration of a situation (Willig, 2008) using multiple sources of evidence which was deemed to be appropriate to understand the differing perspectives. The participating school was chosen using purposive sampling (Cohen et al., 2011) as the research specifically required a secondary school with resource base for students with Asperger syndrome. The chosen school had a resourced provision for ten years with a capacity for twelve students, however at the time of the study thirteen students were enrolled, all of whom were boys. The participants of the study consisted of seven members of staff, which included the head of the resource provision (HoRP), four teachers and two LSAs along with eight parents of the students attending the resource base. We felt that it was important to gather these different perspectives to provide a comprehensive picture of the research focus.

As one of the aims of the study was to find out which practices are in place, a documentary analysis of the school's policies regarding students with SEN was carried out to contextualise the findings. Semi-structured interviews were used to gather the views of staff members and questionnaires were used with the parents. The developed questionnaire included both closed and open questions, which meant that parents were given the opportunity to express their personal opinions, reducing the limitations of pre-set categories (Cohen et al., 2011). It was assumed that the increased anonymity provided by the questionnaires was likely to lead to more 
honest responses from the parents. Out of the thirteen questionnaires sent out, eight were filled in and returned via a self-addressed envelope. All ethical principles such as seeking informed consent, providing anonymity and confidentiality were followed in the research.

\section{Discussion of findings}

The data from all the three sources was analysed using thematic analysis. The findings identified five key themes which all relate to aspects of schooling which affect the students' social inclusion, whether directly or indirectly. These are; learning social skills, a safe place, peer awareness of children with Asperger syndrome, LSA support, and attitudes to inclusion; which will be used to present the data.

\section{Learning social skills}

In line with the school's behaviour policy, it was found that students from the resourced provision are given additional support via a social skills programme and the use of Comic Strip conversations (Gray, 1998). The majority of parents reflected on the positive effects of social skills training which their child receive stating that it

'teaches the art of conversation, understanding body language, facial expressions and how to interact with others'. (Parent 2)

and that this is

linked to particular difficulties they are having and appropriate developmental stage they are at'. (Parent 7)

In addition, members of staff stressed that the children's social skills are constantly monitored and developed throughout the school day:

"Informally we are teaching social skills all the time, from the minute they walk in the door to the minute they go home....because we're watching, we're listening" (HoRP)

'You are developing students' social skills anyway through that mainstream stuff" (Teacher 1) 
"They're taught in terms of group-work, this is how we do group-work, and from the very beginning, so those sorts of social skills in a learning environment" (Teacher 3)

These findings support the principle that social skill training is considered to be beneficial to the social inclusion of students with Asperger syndrome by both staff and parents. It also highlights the benefit of having a resourced provision with skilled staff who have the time, resources and expertise to deliver such training. However alongside this, it identifies that members of staff regard exposure to the mainstream environment as an important method of learning social skills. The acquisition of these skills from exposure to a mainstream environment is not frequently discussed in the literature in relation to children with autism, however, it is generally accepted that students benefit socially and academically from being in the mainstream (Farrell, 2001). The staff in this setting were suggesting that schools should strike a balance between teaching social skills formally and letting them develop naturally through exposure.

\section{$\underline{\text { A safe place }}$}

The findings indicate that not all students with Asperger syndrome required a safe space:

"We have one or two who always choose not to be in the unit and they are the two more confident [...] they're able to go out and spend break times outside and manage it well. The ones that don't feel they can manage actually come in here [the resource centre] and they are very happy to do so, they're very sociable actually, and they're very friendly toward each other" (LSA 2)

"Some of them, you know, are quite happy to be out with their mates, while other-ones are happier being in here, but that's a choice that they have, and I think that's probably the sensible thing about it, it's a choice that they make" (Teacher 2)

On the other hand as suggested in the literature (Tobias, 2009; Wainscot et al. 2008; Humphrey and Symes, 2010) some students preferred having a quiet room in which they could spend their unstructured times. 
"I think because this is a nice quiet safe place and they can be themselves, they've said that themselves, that they can be autistic in here, and everybody knows and nobody minds" (LSA 1)

"I think if they want to come in and feel safe then they come in, I think the majority do, the odd one or two maybe go out, but I think the majority come in" (Teacher 3)

As suggested in the literature, having a safe, quiet place does seem to be important for some students. Having the resourced provision at this school means that unstructured times can be spent either alone, or with other students who have Asperger syndrome. However, considering the previous section where members of staff stated exposure to the mainstream environment as a crucial method of learning social skills, it can be queried whether having a resourced provision which students use to escape the mainstream school is actively encouraging the social exclusion for such students. It also highlights that even though all the students had the same condition, individual preferences vary, and it is important to pay attention to these differences to provide an environment where the children can thrive.

\section{Peer awareness}

The staff stated that although neuro-typical students have an awareness of the resourced provision on site, they generally have little or no understanding of what having autism meant.

"I don't think they really understand the spectrum, let's say, but I think they know because all the boys have an LSA" (Teacher 2)

"I don't think they always understand what Asperger's is... they do know that they're slightly different" (LSA 2)

It appeared that the reason students are not directly informed about autism is based on respecting the child's rights to privacy:

"...when students come into the school, they are aware that they are different, but they also want to be like everyone else. So there is a bit about respecting their own confidentiality about what they want other people to know and what they don't want them to know" (HoRP) 
Since labels can lead to social disadvantage (Gillman et al., 2000) and often cause misunderstood stereotypes (Humphrey, 2008), it is not surprising that the school choose to keep the students' diagnosis confidential. However, as discussed above, it has been often stated that raising peer awareness is an important aspect for social inclusion. Lack of awareness amongst neuro-typical students about their peers with Asperger syndrome sometimes had a negative impact in this setting. Explaining these consequences a teacher said;

"I think that sometimes they don't necessarily know how to handle them, they might be sometimes a little bit - scared is maybe a strong word - but certainly anxious or apprehensive about what to say or do in their company, if they don't understand what they are doing" (Teacher 2)

Another LSA stated;

"I think they're often labelled with the weird, odd, and perceived as not cool to be friends with I think" (LSA 1)

It appears that not disclosing the diagnosing of these students is actually leading to informal labels and creating social barriers. Parents were not sure whether neurotypical peers were aware of their child's diagnosis, and some expressed concerns regarding negative peer interaction:

"My child receives negative peer interaction as a result of his behaviours some children 'wind him up'. Not sure if this is specifically due to being on the spectrum or just his behaviours" (Parent 5)

"There have been times where he has been picked on or led into situations he didn't understand because of being vulnerable to misunderstandings and being over sensitive" (Parent 7)

There seems to be contradictory expectations between teaching staff and parents with regards to disclosing the diagnosis. It seems then that as Betts et al., (2007) suggested to prevent bullying and isolation, parents and some teaching staff believe that schools should focus on raising peer awareness of the student's unique needs as well as providing an explanation of autism. This notion is supported in the present study by one of the LSAs: 
'You get some children that are just, just don't understand why they're behaving differently [....] so yes they do, they do need to know because they need to know why they are displaying the behaviour that they are displaying and understanding why they are doing it" (LSA 2)

While there was evidence that class discussions are held by the Head of the centre when negative situations arise, perhaps it would be more useful to take preventive measures to avoid unpleasant experiences. However, how can peer awareness be raised without labelling the students attending the resource base is a dilemma that this centre is struggling with, as many others across the country.

\section{$\underline{\text { LSA support }}$}

Both the behaviour policy and the SEN policy of the school reflect the need to provide additional support for students from the resourced provision. It was found that the majority of support comes from having LSAs during mainstream lessons. However, there was significant evidence in the data that the LSAs attempt to prevent stigmatisation of students by helping others in the class as these LSAs state:

"It's not a cool thing to have an LSA, not generally, and it depends on the child, I mean some of them are absolutely fine, some are completely oblivious to the uncool factor, whereas some are very conscious of having an LSA and you have to be very different in their lessons" (LSA 1)

"What we try and do is mix, and help other children so that the focus is not all on the Asperger's child. Then we become more accepted as the class help rather than just that child, and I think it makes that child feel better as well" (LSA 2)

However, views differed amongst the staff as can be seen from this teacher's comment.

"Other students don't batter an eyelid. They're just used to it, they're not the only ones who have LSA help either, other people have LSA help, and very frequently they will have another adult in the room, going around helping whoever, so you know I don't think it's a problem actually at all." (Teacher 2) 
It seems then that LSAs in this study were practising what Alborz et al., (2009) suggested about the importance of being a general helper rather than being attached to the child and were aware that this can improve social inclusion and prevent stigmatising, but this view was not held by all members of the staff in this setting.

\section{Attitudes to Inclusion}

The data from the questionnaires with parents found that the majority of them chose this school for their child specifically due to the resourced provision, because:

"This school was able to provide ASD support and academic challenge" (Parent 5)

"Provided the specialist support necessary to suit child's needs" (Parent 4)

It seems parents were influenced in their choice of school by the perceived amount of support available. These views of having additional support also influenced their perceptions of the quality of their child's social experiences:

"[name of child] benefits from being in lessons in the mainstream school along with all his peers. At the same time he has the support of the resource to enable him to achieve this" (Parent 2)

"He is completely integrated within the mainstream lessons and treated equally, whilst also able to receive extra support when needed" (Parent 3)

These views are similar to those found by Whitaker (2007), that parents are more optimistic towards inclusive provision for their child due to the added support from the resource. However, it was unclear whether they considered that such a provision actually encourages the social inclusion of their child.

Similarly, it was found that having a resourced provision influenced staff attitudes towards inclusion, overall staff members linked the additional support available to a positive social experience for students with Asperger syndrome:

"I think that that support, that resourced provision, that works, you know, those students come out with good to excellent GCSE results and things like that, but they also come out of it as well rounded individuals who, again, slot into some of the boxes that society dictates..." (Teacher 1) 
This supports the literature which correlates the perceived amount of support in schools with positive staff attitudes on inclusion (Emam and Farrell, 2009; Humphrey and Lewis, 2008). However, the findings were inconsistent, as there was evidence that some members of staff still perceived inclusion as not working for all students on the spectrum:

"I am a believer in inclusion I do think that, you know, a blind student or a deaf student should be able to access mainstream like everybody else [...] but with [name of child] his maturity level and understanding does have an impact on him, and he's a rare case I would say, but honestly I don't know [if the current school is more beneficial than a special school]" (Teacher 3 )

Similarly another teacher said;

"I think there's been times with a couple of the students where it's been like, you know, can we really do this. Are we specialist enough, do we have enough time, or, are they in the right place." (Teacher 4)

It appears then that some members of staff feel that inclusion within a mainstream school, even with a resourced provision, does not always work for all students with autism. Staff with both views considered successful inclusion to be related to academic achievement and not necessarily with social inclusion.

\section{Limitations and conclusion}

Although most of the staff involved in the resource base and parents of the children in the base were included, this study is based in one school setting and has a relatively small sample size. It will be hard to generalise the findings from this study to all resource bases across the country. This study did not involve student voice to find out how they experience social inclusion. This would be an area that future studies should focus on.

In spite of these limitations, the study does provide insights on the impact of a resource base for social inclusion of students with Asperger syndrome in a secondary school. This study builds upon existing knowledge of the strategies which can help in promoting the social inclusion of students on the autism spectrum in mainstream secondary schools. These include teaching social skills, having a safe 
space and LSAs providing class support as opposed to 1:1 support. It also highlights the tension involved in raising peer awareness about a child's SEN. As the views around this varied across the staff and the parents, this may have to be done in a sensitive way. However, there should still be whole school awareness opportunities in successful social inclusion has to take place.

The findings support what was found in previous studies that the perceptions of the success of inclusion by both staff and parents can be influenced by the perceived level of support available in school. In general, having a resourced provision meant that staff members and parents perceived a positive experience of schooling for students with Asperger syndrome, however the findings were inconsistent and reflected some teachers' reservations about mainstream schools being able to meet the needs of all individuals on the spectrum. This highlights that in spite of having resources within school, teachers attitudes can vary on the issue of inclusion. Staff also focused more on the academic achievement rather than the social inclusion which relates to the existing confusion in the definition of the term inclusion. It appears then that even in a condition where social difficulties are considered as a core area of need; social inclusion is not always the priority in school settings and that even with additional support not all teachers feel that inclusion is the best approach for all children with autism. Both these findings highlight the importance of continuing to raise awareness of autism spectrum within mainstream schools in the UK and considering alternative ways of supporting this young people.

\section{References}

Alborz, A., Pearson, D., Farrell, P. and Howes, A. (2009) The Impact of Adult Support Staff on Pupils and Mainstream Schools: a systematic review. [Online] Available at:

http://eppi.ioe.ac.uk/cms/LinkClick.aspx?fileticket=w423SGddbGM\%3d\&tabid=2438 \&mid=4540 (Accessed on $21^{\text {st }}$ February 2016)

Avramidis, E. and Norwich, B. (2002) 'Teachers attitudes towards integration/inclusion: a review of the literature', European Journal of Special Needs Education, 17 (2), 129-147 
Boutot, E.A. (2007) 'Fitting in: tips for promoting acceptance and friendships for students with autism spectrum disorders in inclusive classrooms', Interventions in School and Clinic, 42 (3), 151-161

Cappadocia, M.C., Weiss, J.A. and Popler, D. (2012) 'Bullying experiences among children and youth with autism spectrum disorders', Journal of Autism and Developmental Disorders, 42, 266-277

Cohen, L., Manion, L. and Morrison, K. (2011) Research Methods in Education. (7 $7^{\text {th }}$ edn.) Oxon: Routledge

DfE (2011) Support and Aspiration: A new approach to special educational needs and disability. London: The Stationery Office.

Dybvik, A.C. (2004) 'Autism and the inclusion mandate: what happens when children with severe disabilities like autism are taught in regular classrooms? Daniel knows', Education Next, 42 (8), 43-49

Emam, M.M. and Farrell, P. (2009) 'Tensions experienced by teachers and their views of support for pupils with autism spectrum disorders in mainstream schools', European Journal of Special Needs Education, 24 (4), 407-422

Farrell, P. (2001) 'Special education in the last twenty years: have things really got better?', British Journal of Special Education, 28 (1), 3-9

Farrell, P., Dyson, A., Polat, F., Hutcheson, G. and Gallannaugh, F. (2007) 'SEN Inclusion and pupil achievement', Journal of Research in Special Educational Needs, 7 (3), 172-178

Frederickson, N. and Furnham, A. (2004) 'Peer-assessed behavioural characteristics and sociometric rejection: Differences between pupils who have moderate learning difficulties and their mainstream peers', British Journal of Educational Psychology, 74 (3), 391-410

Frederickson, N., Jones, A.P. and Lang, J. (2010) 'Inclusive provision options for pupils on the autistic spectrum', Journal of Research in Special Educational Needs, $10(2), 63-73$ 
Gillman, M., Heyman, B., and Swain, J. (2000) 'What's in a name? The implications of diagnosis for people with learning difficulties and their family carers', Disability and Society, 15, 389-409

Gray, C. (1998) 'Social Stories and Comic Strip Conversations with students with Asperger Syndrome and High Functioning Autism.' In: E. Schopler, G. Mesibov \& L. Kunce (Eds.), Asperger Syndrome or High Functioning Autism? (pp. 167198). New York: Plenum Press

Great Britain. Parliament. House of Commons. (2006) Special Educational Needs, Third Report of Session 2005-2006. London: The Stationery Office. (HC 478-1)

Humphrey, N. (2008) 'Including pupils with autistic spectrum disorders in mainstream schools', Support for Learning, 23 (1), 41-47

Humphrey, N. and Lewis, S. (2008) 'What does inclusion mean for pupils on the autistic spectrum in mainstream secondary schools?', Journal of Research in Special Educational Needs, 8 (3), 132-140

Humphrey, N., and Parkinson, G. (2006) 'Research on interventions for children and young people on the autistic spectrum: a critical perspective', Journal of Research in Special Educational Needs, 6 (2), 76-86

Humphrey, N. and Symes, W. (2010) 'Responses to bullying and use of social support among pupils with autism spectrum disorders (ASDs) in mainstream schools: a qualitative study', Journal of Research in Special Educational Needs, 10 (2), 82-90

Jones, A. P. and Frederickson, N. (2010) 'Multi-informant predictors of social inclusion for students with autism spectrum disorders attending mainstream school', Journal of Autism and Developmental Disorders, 40 (9), 1094-1103

Jones, G., English, A., Guldberg, K., Jordan, R., Richardson, P. and Waltz, M. (2008) Education Provision for children on the autistic spectrum living in England: a review of current practice, issues and challenges. London: Autism Education Trust Jordan, R. (2005) 'Managing autism and Asperger's syndrome in current educational provision', Pediatric Rehabilitation, 8 (2), 104-112 
Jordan, R. (2008) 'Autistic spectrum disorders: a challenge and a model for inclusion in education', British Journal of Special Education, 35 (1), 11-15

Kalambouka, A., Farrell, P., Dyson, A. and Kaplan, I. (2007) 'The impact of placing pupils with special educational needs in mainstream schools on the achievement of their peers', Educational Research, 49 (4), 365-382

Lewis, A. (1993) 'Integration, education and rights', British Educational Research Journal, 19 (3), 291

Locke, J., Ishijima, E.H., Kasari, C. and London, N. (2010) 'Loneliness, friendship quality and the social networks of adolescents with high-functioning autism in an inclusive school setting', Journal of Research in Special Educational Needs, 10 (2), 74-81

Moore, C. (2007) 'Speaking as a parent: thoughts about educational inclusion for autistic children', in Cigman, R. (eds), Included or Excluded? The Challenge of Mainstream for some SEN Children, 34-41. London: Routledge

Myles, B., and Simpson, R. (2001), 'Understanding the hidden curriculum: an essential social skill for children and youth with Asperger Syndrome', Intervention in School and Clinic, 36 (5), 279-286

Ofsted (2006) Inclusion: Does it matter where pupils are taught? [Online] Available at: https://www.education.gov.uk/publications/.../HMI-2535.doc.doc (Accessed on $21^{\text {st }}$ February 2015)

Park, M., and Chitiyo, M. (2009) 'A Proposed Conceptual Framework for Teachers' Attitudes towards Children with Autism', Southeastern Teacher Education Journal, 2 (4), 43-56

Rix, J., Hall, K., Nind, M., Sheehy, K. and Wearmouth, J. (2009) 'What pedagogical approaches can effectively include children with special educational needs in mainstream classrooms? A systematic literature review', Support for learning, 24 (2), 86-94 
Symes, W. and Humphrey, N. (2010) 'Peer-group indicators of social inclusion among pupils with autistic spectrum disorders (ASD) in mainstream secondary schools: a comparative study', School Psychology International, 31 (5), 478-494

Thorpe, A. and Shafiul Azam, A.Q.M. (2010) 'Teachers' perceptions of inclusive education in mainstream primary schools in the United Kingdom', The International Journal of Interdisciplinary Sciences, 5 (3), 163-172

Tobias, A. (2009) 'Supporting students with autism spectrum disorders at secondary school: a parent and student perspective', Educational Psychology in Practice, 25 (2), 151-165

Wainscot, J.J., Naylor, P., Sutcliffe, P., Tantam, D. and Williams, J.V. (2008) 'Relationships with peers and use of the school environment of mainstream secondary school pupils with Asperger Syndrome (high-functioning autism): a casecontrol study', International Journal of Psychology and Psychological Therapy, 8 (1), 25-38

Warnock, M. (2010) 'Special Educational Needs: A New Look', in Warnock, M. and Norwich, B. (eds) Special Educational Needs: A New Look, pp. 11-46. London: Continuum

Whitaker, P. (2007) 'Provision for youngsters with autistic spectrum disorders in mainstream schools: what parents say - and what parents want', British Journal of Special Education, 34 (3), 170-178

Willig, C. (2008) Introducing Qualitative Research in Psychology, (2nd edn.) Maidenhead: Open University Press 